\title{
Prevalence and factors associated with use of herbal medicines during pregnancy among women attending postnatal clinics in Gulu district, Northern Uganda
}

Richard Nyeko ${ }^{1 *}$, Nazarius Mbona Tumwesigye ${ }^{2}$ and Abdullah Ali Halage ${ }^{3}$

\begin{abstract}
Background: According to World Health Organization (WHO) estimates, $80 \%$ of the population living in rural areas in developing countries depends on traditional medicine for their health needs, including use during pregnancy. Despite the fact that knowledge of potential side effects of many herbal medicines in pregnancy is limited and that some herbal products may be teratogenic, data on the extent of use of herbal medicines by women during pregnancy in the study setting is largely unknown. We determined the prevalence and factors associated with herbal medicine use during pregnancy among women attending postnatal clinics in Gulu district, Northern Uganda.
\end{abstract}

Methods: This was a descriptive cross-sectional study which involved 383 women attending postnatal care across four sites in Gulu district using quantitative and qualitative methods of data collection. A structured questionnaire was used to collect quantitative data while qualitative data were obtained using focus group discussions and key informant interviews. The selection of the study participants was by systematic sampling and the main outcome variable was the proportion of mothers who used herbal medicine. Quantitative data was coded and entered into a computerized database using Epidata 3.1. Analysis was done using Statistical Package for Social Scientists version 13, while thematic analysis was used for qualitative data.

Results: The prevalence of herbal medicines use during the current pregnancy was $20 \%$ (78/383), and was commonly used in the second $23 \%(18 / 78)$ and third $21 \%(16 / 78)$ trimesters. The factors significantly associated with use of herbal medicines during pregnancy were perception (OR 2.18, Cl 1.02-4.66), and having ever used herbal medicines during previous pregnancy (OR 2.51, Cl 1.21-5.19) and for other reasons (OR 3.87, Cl 1.46-10.25).

Conclusions: The use of herbal medicines during pregnancy among women in Gulu district is common, which may be an indicator for poor access to conventional western healthcare. Perception that herbal medicines are effective and having ever used herbal medicines during previous pregnancy were associated with use of herbal medicines during current pregnancy. This therefore calls for community sensitization drives on the dangers of indiscriminate use of herbal medicine in pregnancy, as well as integration of trained traditional herbalists and all those community persons who influence the process in addressing the varied health needs of pregnant women.

Keywords: Herbal medicines, Pregnancy, Maternal health services, Maternal mortality

\footnotetext{
*Correspondence: richard_nyeko@yahoo.com

'Department of Paediatrics and Child Health, St. Mary's Hospital Lacor, P.O

Box 180, Gulu District, Uganda

Full list of author information is available at the end of the article
} 


\section{Background}

The use of herbal medicines is believed to be increasing in many developing and industrialized countries, yet little is known about their use and safety especially during pregnancy [1]. Herbal medicines in this case are defined as plant-derived material and preparations perceived to have therapeutic benefits, containing raw or processed ingredients from one or more plants [2], and include herbs, herbal materials, herbal preparations, and finished herbal products that contain parts of plants or other plant materials as actual ingredients [3]. It is estimated that $80 \%$ of the population living in rural areas in developing countries depends on traditional medicine for their health needs [4,5], including use during pregnancy. While use of herbal medicines in pregnancy vary considerably between countries, many of the same herbs are used [6]. Evidence from the African continent suggests wide variability in use of herbal medicines during pregnancy, from a high of about $68 \%$ as reported in one Nigerian study [7] to a low of $12 \%$ in another study [8]. In Lusaka, Zambia, $21 \%$ of pregnant women seeking care in public health system used traditional medicines during pregnancy [9].

In Uganda, it is estimated that over $60 \%$ of the population seek medical attention from traditional healers, a pattern which cuts across all social classes and education levels [4], where traditional herbal medicine is widely used for prevention, diagnosis and treatment of social, mental and physical illnesses [10]. Majority of patients in Gulu district, including pregnant women are suspected to use traditional herbal medicines for a number of ailments, but the actual burden of use of herbal medicines by women during pregnancy is still unknown. In the same breath, use of herbal medicine is believed to be a contributing factor to poor access to, and use of, maternal healthcare services, including antenatal care (ANC) services and health facility delivery that are aimed at reduction of maternal death, currently at 438 per 100,000 live births [11], indicating that Uganda is unlikely to meet the millennium development goal (MDG) 5. For instance, whereas over $90 \%$ of pregnant women attend at least one ANC visit, only about $47 \%$ attend the World Health Organization (WHO)-recommended four or more ANC visits during their pregnancy [12], and only $57 \%$ give birth in a health facility [11], suggesting possibility of resorting to alternative methods of health care, including use of herbal medicines. According to a report by Lamorde et al. (2008) in a study of medicinal plants used for HIV/AIDS related conditions in Gulu and other selected Ugandan disctrics, the most frequently used herbal medicine plant species include Aloe sp, Erythrina abyssinica DC, Sarcocephalus latifolius, Psorospermum febrifugum spach, Mangifera indica L, and Warburgia salutaris [13].
Like modern pharmaceutical drugs, herbal medicines, however, have the potential to cause adverse effects [14]. The causes of such adverse reactions are diverse, including the use of inherently toxic herbal medicines or an overdose of herbs, conventional drug-herbal medicine interactions, and idiosyncratic reactions such as allergies [15]. Therefore, relying on herbal medicines during pregnancy instead of scientifically proven treatment can have serious consequences, suggested to include fetal distress and premature deliveries [16], intrauterine growth restriction and decreased fetal survival [17], and congenital malformations [18], among others. Also among the variety of biological properties of herbal medicines is the ability to contract the uterus thereby posing the risk of abortion [19]. Furthermore, concomitant use of herbal products with the pharmaceutical medications leads to drug interactions with resultant undesirable effects of increased toxicity and decreased efficacy.

Despite the fact that knowledge of potential side effects of many herbal medicines in pregnancy is limited $[1,20-22]$, and that some herbal products may be teratogenic [23-25], exposure to herbal products is frequent in pregnancy [26], often on a self-treatment basis [27]. Similarly, while pregnant women recognize the potential risks of drug usage during pregnancy, they do not realize that herbal products could also be toxic, premised on the implicit belief that herbal products, being natural, are necessarily safe [28]. The use of herbal medicines in general, and in pregnancy in particular has been contributed to by a number of factors, including the belief that herbal products are safe and general ease of access [29], lack of access to public health system [5] and high cost of modern healthcare, perceived low costs of herbal products, socio-demographic characteristics, and social and cultural influences, among others $[30,31]$. On the other hand, women who seek abortion may deliberately use the frequently unsafe traditional herbal products to induce fetal loss [2]. For instance, in one study of unsafe abortion in rural Tanzania, almost half of the women who experienced an unsafe abortion had resorted to traditional providers and plant species were in these cases often used as abortion remedies [32]. This study therefore seeks to determine the prevalence and factors associated with use of herbal medicines during pregnancy among women attending postnatal clinics in Gulu district, northern Uganda.

\section{Methods}

\section{Study setting}

The study was conducted in four (4) selected health facilities in Gulu district, northern Uganda, with a population of 479,496 inhabitants [33]. The main economic activity in the district is subsistence agriculture, in which over $90 \%$ of the population is engaged. The district has 
one government regional referral hospital, two private hospitals, two health centre IVs and thirteen health centre IIIs which provide maternal health services including postnatal care services. However, access to health services still remains a challenge in the district as a whole. Over $37 \%$ of the population moves a distance of more than $5 \mathrm{~km}$ to reach health services. High levels of poverty and illiteracy, especially among women, is exacerbated by high prevalence of preventable diseases.

\section{Study design and sample size}

This was a descriptive cross-sectional study, using both quantitative and qualitative methods, and involving 383 postnatal mothers attending postnatal clinics (PNC) within the study period. The sample size was calculated using the Kish Leslie formula [34], using the formula, $n=\mathrm{z}^{2} \mathrm{pq} / \mathrm{d}^{2}$, where $n=$ required sample size, $\mathrm{z}=$ standard normal value corresponding to $95 \%$ confidence interval (1.96), $p$ =estimated proportion of herbal medicine use among pregnant women, which in this case is $21 \%$ [9], $\mathrm{q}=\mathrm{p}-1$, and $\mathrm{d}=$ absolute errors between estimated and true value (5\%). This was multiplied by a design effect of 1.5 , giving a total sample size of 383. The study population consisted of women attending postnatal clinic in the facilities in Gulu district during the study period. Women who were critically sick at the time of the visit (5 respondents) and those who were not able to understand the questions because of language barrier ( 2 respondents) were excluded.

\section{Sampling technique}

Multistage sampling technique was used to select first, the health facilities for the study, and later, the respondents from each facility selected. The health facilities were first grouped into three strata comprising hospitals, health center IVs and health center IIIs. The only public hospital together with the two private hospitals were all grouped as one stratum of 'hospitals'. Simple random sampling was then used to select the desired number of facility from each stratum where two hospitals and one health center each from the health center IV and III strata were selected as sites for the study. The determination of the number of health facilities chosen from each stratum was purposive in order to keep the research within the scope. The selection of the study participants from each of the sampled health facility was done by systematic sampling until the required sample size was realized. According to a preliminary survey of records from the health facility postnatal registers, it was estimated that about 20 mothers attend the PNC daily in hospitals and health center IVs (HCIVs), while about 10 attend in health center IIIs (HCIIIs). We therefore recruited 6 participants each day from the hospitals and HCIVs, and 3 from health center III. Therefore, every third mother (20/6 and 10/3 for hospitals/HCIV and HCIII respectively) was selected for the study, with the first participant being picked at random from assigned numbers. The selected mothers were then introduced to the study in more details, including the working definition of herbal medicine, and informed consent obtained for participation in the study before enrollement.

\section{Study procedure and data collection}

A pre-coded and pre-tested structured questionnaire to capture respondents' demographic characteristics, obstetrics characteristics, herbal medicine use during pregnancy and associated factors, and characteristics of herbal medicine use was used to collect quantitative data, while qualitative data were collected from focus group discussions (FGD) and key informant interviews (KII) using FGD and KII guides respectively. The questionnaires and interview guides were written in English as well as translated and administered in the local language understood by the participants.

For qualitative data, three focus group discussions (FGDs) were conducted in the community involving women who had not been part of the quantitative study in order to get a local perspective of the subject matter. Eight mothers were included in each of the FGDs. The groups involved mothers in the age group 20-38 years excluding grandmothers and mothers-in-law who usually have great influence in this community, in order to allow free expression of views. The discussions were moderated by the researcher and recorded on tape as well as notes taken by a rapporteur. Four key informants comprising one village health team (VHT), one local council one and two midwives were selectively interviewed to get a broader perspective of the aspects of herbal medicine use during pregnancy.

\section{Statistical analysis \\ Quantitative data}

Data were coded and entered into a computerized database using Epidata 3.1. Data were cleaned and analysis was done at three levels using Statistical Package for Social Scientists (SPSS) version 13 software package. In univariate analysis, categorical variables were summarized as proportions, while continuous variables as means, median and standard deviations (SD). Prevalence was calculated as the proportion of study participants who used herbal medicines, the denominator being all postnatal mothers enrolled in the study. In the bi-variate analysis, the chi-square test (for categorical variables) and student $t$-test (for continuous variables) were used to test if the factors among mothers who used herbal medicines during pregnancy were different from those among mothers who did not use herbal medicines. Odds ratios, with $95 \%$ confidence interval $(\mathrm{CI})$ was used to measure the strength of 
association between use of herbal medicines during pregnancy and individual, socio-cultural, obstetrics/maternal, and health systems factors.

Multivariable analysis using logistic regression, backward stepwise procedure was used to select variables to be included in the final model to determine the factors that were independently associated with use of herbal medicine during pregnancy. Included in the model at multivariable analysis were factors that were significant at bivariate analysis and those with scientific plausibility though were not significant. $P$-value $<0.05$ was considered for statistical significance. Results were summarized in bar graphs, tables, and texts.

\section{Qualitative data}

Qualitative information generated from the FGDs and Key informant interviews were analyzed manually using thematic analysis according to emerging themes. Transcribed data were coded and main emerging themes were identified and presented as text quotes.

\section{Results}

\section{Socio-demographic characteristics}

Three hundred and eighty three respondents were enrolled in the study (Fig. 1). Majority, $41 \%(156 / 383)$ of the respondents were between 20 and 24 years of age and at least $15 \%(56 / 383)$ were teen mothers (15-19 year old), $70 \%(39 / 56)$ of whom were in the legally recognized marriage age of 18-19 years. More than three-quarter of the respondents, $76 \%(290 / 383)$ attained either no formal education or just primary level of education and majority $74 \%(282 / 383)$ were residing in rural settings. The rest of the socio-demographic characteristics of the respondents are as summarized in Table 1. While all except two of the respondents attended antenatal care (ANC), only about half $49 \%(186 / 383)$ had the recommended $\geq 4$ goal-oriented ANC attendances. The other obstetrics characteristics of the respondents are summarized in Table 2.

\section{Qualitative findings}

The single most common theme that emerged from the qualitative data was facilitators of herbal medicine use, in addition to disclosure of herbal medicine use which also emerged as an issue to the respondents. The facilitator theme describes the factors that encouraged the use of herbal medicines and included belief that herbal medicines are effective in treating many ailments, previous experience with herbal medicines, cost of modern healthcare, and dissatisfaction with the healthcare system, among others. The disclosure theme mainly describes the respondents' reasons for not volunteering information about use of herbal medicine to their healthcare providers and included fear of the health workers reaction, and being denied care. The two themes are described verbatim in quotes in triangulation with the quantitative data in the sections below.

\section{Prevalence of herbal medicine use}

The prevalence of herbal medicine use during the current pregnancy was $21 \%$ (78/383), while use of herbal medicines in general is common in the study setting (Fig. 2). Ingestion was the major method of use of herbal medicines $69 \%(54 / 78)$ and majority $90 \%(70 / 78)$ of the users of herbal medicines did not disclose the use of these local herbs to their attending healthcare workers at ANC and delivery (Table 3). Views during the FGDs did not differ much from the above finding, as reported by one of the mothers:

"For me I think it is not possible to tell the health workers that you took local herbs because they can

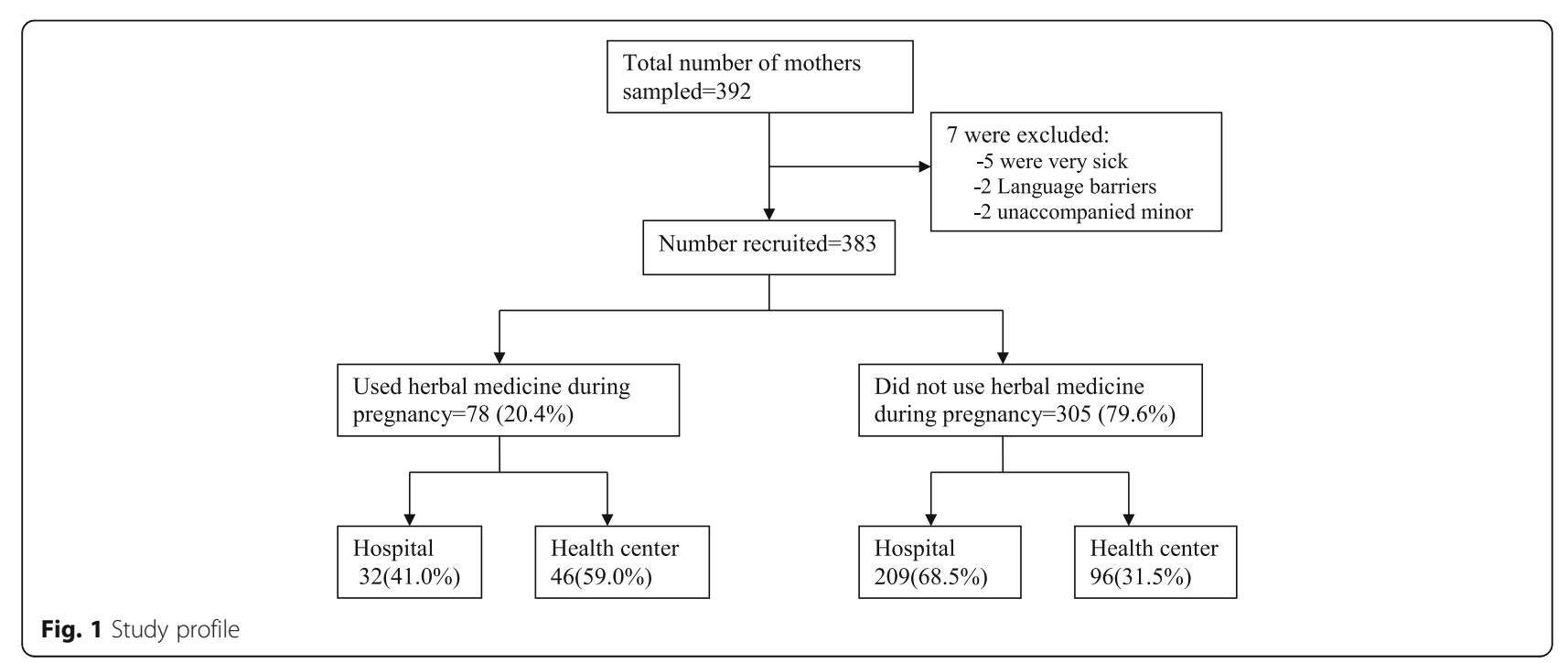


Table 1 Baseline socio-demographic characteristics of the study population

\begin{tabular}{|c|c|c|}
\hline Variable & Frequency $(N=383)$ & Percent \\
\hline Mean age & $25.32(6.16)^{\mathrm{a}}$ & \\
\hline \multicolumn{3}{|l|}{ Age group (years): } \\
\hline$<34$ & 339 & 88.5 \\
\hline$\geq 35$ & 44 & 11.5 \\
\hline \multicolumn{3}{|l|}{ Occupation: } \\
\hline Peasant & 292 & 76.2 \\
\hline Others & 91 & 23.8 \\
\hline \multicolumn{3}{|l|}{ Marital status: } \\
\hline Married & 246 & 64.2 \\
\hline Not married & 137 & 35.8 \\
\hline \multicolumn{3}{|l|}{ Education level: } \\
\hline Tertiary & 22 & 5.7 \\
\hline Below tertiary & 361 & 94.3 \\
\hline \multicolumn{3}{|l|}{ Religion: } \\
\hline Catholic & 268 & 70.0 \\
\hline Others & 115 & 30.0 \\
\hline \multicolumn{3}{|l|}{ Average monthly income (UGX): } \\
\hline$<75,000$ & 251 & 71.7 \\
\hline$\geq 75,000$ & 99 & 28.3 \\
\hline \multicolumn{3}{|l|}{ Residence } \\
\hline Rural (outside the municipality) & 282 & 73.6 \\
\hline Urban (within the municipality) & 101 & 26.4 \\
\hline \multicolumn{3}{|l|}{ Distance from health facility } \\
\hline$>5 \mathrm{~km}$ & 169 & 44.1 \\
\hline$\leq 5 \mathrm{~km}$ & 214 & 55.9 \\
\hline \multicolumn{3}{|l|}{ Study site } \\
\hline Gulu hospital & 127 & 33.2 \\
\hline Lacor hospital & 115 & 30.0 \\
\hline Awach HCIV & 101 & 26.4 \\
\hline Bobi HCIII & 40 & 10.4 \\
\hline
\end{tabular}

${ }^{\mathrm{a} M e a n}$ (SD)

become rude to you since they say people should come to hospital when they are sick but not to use local medicines. They can also refuse to give you treatment from the hospital if you say you have taken local medicines when you are also receiving care from the hospital." FGD, 20 year old mother.

Similarly, one of the key informants also observed that:

"We sometimes get to know about these mothers using local herbal medicines during labour from the colour of their liquor or traces of the herbs in the genital parts, otherwise they will not tell you that they have used local herbs..." KII, midwife.
Table 2 Obstetrics and other characteristics of the study population

\begin{tabular}{|c|c|c|}
\hline Characteristics & Number & Percent \\
\hline \multicolumn{3}{|l|}{ Parity: } \\
\hline Primiparous & 87 & 22.7 \\
\hline Para $\geq 2$ & 296 & 77.3 \\
\hline \multicolumn{3}{|l|}{ ANC attendance: } \\
\hline Yes & 381 & 99.5 \\
\hline No & 2 & 0.5 \\
\hline \multicolumn{3}{|c|}{${ }^{a}$ Number of ANC attendance: } \\
\hline$<4$ ANC & 195 & 50.9 \\
\hline$\geq 4$ ANC & 186 & 48.6 \\
\hline \multicolumn{3}{|l|}{ Place of delivery: } \\
\hline Health facility & 326 & 85.1 \\
\hline Home & 57 & 14.9 \\
\hline \multicolumn{3}{|c|}{ Opinion about effectiveness \& safety: } \\
\hline Effective/safe & 122 & 31.9 \\
\hline Not effective & 261 & 68.1 \\
\hline \multicolumn{3}{|c|}{ bUsed HM during previous pregnancies: } \\
\hline Yes & 121 & 35.7 \\
\hline No & 218 & 64.3 \\
\hline \multicolumn{3}{|c|}{ Ever used HM for other reasons } \\
\hline Yes & 208 & 54.3 \\
\hline No & 175 & 45.7 \\
\hline
\end{tabular}

Majority of users of herbal medicines during pregnancy had multiple reasons for use of these medicines, with the most common indications being abdominal/ waist pain (43\%), febrile illness (45\%), inducing/enhancing labour (28\%), skin problems (24\%), nausea and vomiting (22\%), and difficult access to health facility (41.3\%), amomg others, as summarized in Table 4. The wide use of herbal medicines for various indications was also exemplified in one of the FGDs where one respondent asserted thus:

“...local herbs work as well as other medicines. It works in waist pain, perianal wounds in children and "twor rubanga" (TB spine). I had a painful period and when I tried the hospital the medicines did not work but when somebody gave me local herbs, it subsided." FGD, 28 year old mother of four.

\section{Factors associated with herbal medicine use}

At bivariate analysis, mothers who believed in herbal medicines were ten times more likely to use herbal products during pregnancy than those believing otherwise and this was statistically significant (OR 10.02; $95 \%$ CI 


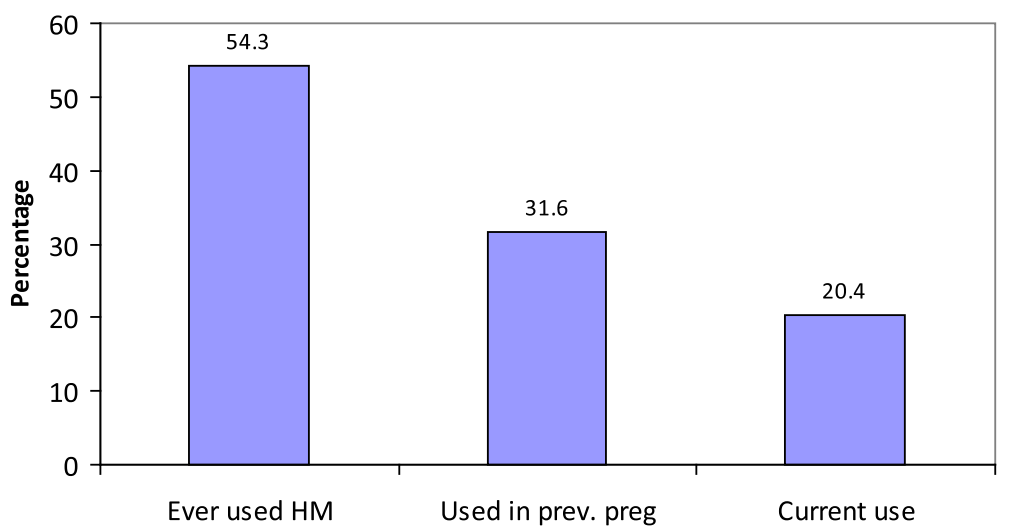

Fig. 2 Prevalence of herbal medicine use by respondents

5.67-17.73). This finding was supported by results from the FGDs where one of the respondents reported:

"I was told that the local herbs are the ones made into modern medicines, so they should work the same way. I have used local herbs for all my ailments, including during my previous pregnancies and I have not experienced any problems. It is true people take local herbs for many illnesses and they get cured, sometimes even if you are taken to the hospital, the doctor can even say go back for local herbs because they cannot manage that condition." FGD, 35 year old mother.

Similarly, ever having used herbal medicines for other reasons was significantly associated with use of herbal medicines during the current pregnancy. The other individual and socio-cultural factors associated with use of herbal medicines among the respondents are as summarized in Table 5.

Parity showed a statistically significant negative association with use of herbal medicines during pregnancy (OR 0.50; $95 \%$ CI 0.25-0.98), implying women who are first time mothers were less likely to use herbal medicines during pregnancy. Women who used herbal medicines in their previous pregnancies were eight times more likely to use herbal medicines in their current pregnancies and this was statistically significant (OR 7.98; 95 \% CI 4.45-14.30). Similarly, residing more than $5 \mathrm{kms}$ from the nearest health facility was more likely to be associated with use of herbal medicine during pregnancy and this was statistically significant (OR 2.43; 95 \% CI 1.46-4.05) (Table 6). This finding was supported by results from the FGDs as typified by one respondent who, in expressing her concern, observed thus:

"You can waste your little money and time going to the health facilities for problems like pain, cough, fever and the only thing they tell you is that there is no medicine, sometimes you only come back with aspirin or panadol, or you can even come back without any medicine and yet you travel from long distance which is expensive. So it is better to first get help from home and maybe only go to the health facility when you have failed to improve." FGD, a mother of five.

Simlilarly, one of the key informants from one of the health facilities reported:

"...some of our mothers come from far distances to receive healthcare services and sometimes they are not able to afford transport money, so they prefer to use local herbs and only come to hospitals at the end..." KII, midwife.

At multivariable logistic regression analysis, belief that herbal medicines are effective/safe, as well as previous use of herbal medicines during pregnancy or for other reasons were the only significant independent predictors of use of herbal medicines during pregnancy in this study. The factors that remained in the model even though were not statistically significant were age, distance from nearest health facility, self-medication and parity (Table 7).

\section{Discussion}

The present study determined the prevalence and factors associated with use of herbal medicines during pregnancy among 383 women attending postnatal clinics in Gulu district, Uganda. Our main findings show that use of herbal medicines during pregnancy in the study setting is common.

\section{Prevalence of herbal medicine use}

The prevalence of herbal medicines use during pregnancy among the postpartum women in the current study is 
Table 3 Characteristics of herbal medicine use during pregnancy

\begin{tabular}{|c|c|c|}
\hline Characteristics & Number $(n=78)$ & Percent \\
\hline \multicolumn{3}{|l|}{ Trimester of pregnancy: } \\
\hline $1^{\text {st }}$ trimester & 6 & 10.3 \\
\hline $2^{\text {nd }}$ trimester & 18 & 23.1 \\
\hline $3^{\text {rd }}$ trimester & 16 & 20.5 \\
\hline $1^{\text {st }}$ and $2^{\text {nd }}$ trimester & 10 & 12.8 \\
\hline $2^{\text {nd }}$ and $3^{\text {rd }}$ trimester & 11 & 14.1 \\
\hline During labour & 9 & 11.5 \\
\hline Throughout pregnancy & 6 & 7.7 \\
\hline \multicolumn{3}{|l|}{ Perception: } \\
\hline Effective/safe & 51 & 82.3 \\
\hline Not effective & 11 & 17.7 \\
\hline \multicolumn{3}{|l|}{ Method of use: } \\
\hline Ingestion & 54 & 69.2 \\
\hline Smearing on abdomen & 15 & 19.3 \\
\hline Insertion in vagina & 6 & 7.7 \\
\hline Inhalation & 3 & 3.8 \\
\hline \multicolumn{3}{|l|}{ Duration of HM use: } \\
\hline$<3$ week & 57 & 73.1 \\
\hline$\geq 3$ weeks & 21 & 26.9 \\
\hline \multicolumn{3}{|l|}{ Paid for herbal medicine: } \\
\hline Yes & 57 & 73.1 \\
\hline No & 21 & 26.9 \\
\hline \multicolumn{3}{|l|}{ Source of herbal medicine: } \\
\hline Gathered from bush & 37 & 47.4 \\
\hline Traditional healer & 39 & 50.0 \\
\hline Others & 2 & 2.6 \\
\hline \multicolumn{3}{|c|}{ Source of information to use HM } \\
\hline Relative & 46 & 59.0 \\
\hline Herbalist & 20 & 25.6 \\
\hline Friend & 12 & 15.4 \\
\hline \multicolumn{3}{|c|}{ Would disclose use of HM to health worker } \\
\hline Yes & 20 & 25.6 \\
\hline No & 58 & 74.4 \\
\hline \multicolumn{3}{|c|}{ Disclosed use of HM to health worker } \\
\hline Yes & 8 & 10.3 \\
\hline No & 70 & 89.7 \\
\hline \multicolumn{3}{|c|}{ Concomitantly used HMs with ANC drugs } \\
\hline Yes & 50 & 64.1 \\
\hline No & 28 & 35.9 \\
\hline
\end{tabular}

HM herbal medicines, ANC antenatal clinic

comparable to one reported by Yolan et al. (2007) in Lusaka, Zambia [9]. The current finding, however, contrasts with results from a similar study in Nigeria where a
Table 4 Reasons for using herbal medicine during pregnancy

\begin{tabular}{|c|c|c|}
\hline Characteristics & Number $^{\mathrm{a}}$ & Percent $^{\mathrm{b}}$ \\
\hline \multicolumn{3}{|l|}{ Obstetrics reasons $(n=106)$ : } \\
\hline Nausea and vomiting & 23 & 21.7 \\
\hline Abdominal/waist pain & 45 & 42.5 \\
\hline Keep the baby healthy & 8 & 7.5 \\
\hline Induce/enhance labour & 30 & 28.3 \\
\hline \multicolumn{3}{|l|}{ Socio-cultural beliefs ( $n=120)$ : } \\
\hline Tradition of use & 43 & 35.8 \\
\hline HM cures many illnesses & 47 & 39.2 \\
\hline Herbs are more efficacious & 15 & 12.5 \\
\hline Herbs are safe in pregnancy & 15 & 12.5 \\
\hline \multicolumn{3}{|l|}{ Health systems $(n=109)$ : } \\
\hline Low cost of herbal medicine & 34 & 31.2 \\
\hline Difficulty accessing health facility & 45 & 41.3 \\
\hline Lack of drugs in health facility & 30 & 27.5 \\
\hline \multicolumn{3}{|l|}{ Concurrent illness ( $n=105)$ : } \\
\hline Respiratory infections & 29 & 27.6 \\
\hline Febrile illness & 47 & 44.8 \\
\hline Skin problems & 25 & 23.8 \\
\hline Other reasons & 4 & 3.8 \\
\hline
\end{tabular}

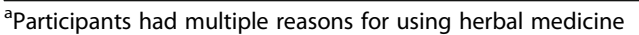

bercentage calculated using the denominator for each category

much higher proportion of women used herbal medicines during pregnancy [7]. The finding from the present study also shows a lower prevalence of use of herbal medicines during pregnancy in comparison with other similar studies $[14,35,36]$; but higher than the prevalence reported by Mothupi (2014) in Kenya [30] and by Gharoro and Igbafe (2000) in another Nigerian study [8]. This could be attributed to the differences in the populations studied, as well as differences in socio-cultural contexts, and health care systems (availability of services, access, and trust) in the different study settings. Furthermore, while Titilayo and colleagues (2009) looked broadly at use of herbal medicines in recent years among pregnant women [7], our study focused on current use, which renders plausible explanation to the likely higher percentage of use reported in their study as compared to that in the present study. Similarly, though Gharoro and Igbafe (2000) studied use of herbs among postnatal women [8], they only considered use of few specific herbs which is likely to explain the relatively lower prevalence of use. Similarly, the relatively lower prevalence of herbal medicine use during pregnancy found in the present study as compared to that from other studies could also be partly attributed to possible nondisclosure. This is supported by the fact that a significant number of respondents in the present study admitted that they would not disclose use of herbal medicine to the healthcare providers if they sought care from herbalists, a 
Table 5 Individual and socio-cultural factors associated with use of herbal medicines

\begin{tabular}{|c|c|c|c|c|}
\hline Characteristics & Used HM N= 78 (\%) & No HM use $N=305(\%)$ & OR (95\% Cl) & $p$-value \\
\hline \multicolumn{5}{|l|}{ Individual factors: } \\
\hline \multicolumn{5}{|l|}{ Age in years: } \\
\hline$<35$ & $65(19.2)$ & $274(80.8)$ & $0.57(0.28-1.14)$ & 0.108 \\
\hline$\geq 35$ & $13(29.5)$ & $31(70.5)$ & 1.0 & \\
\hline \multicolumn{5}{|l|}{ Residence: } \\
\hline Rural & $64(22.7)$ & $218(77.3)$ & $1.82(0.97-3.42)$ & 0.059 \\
\hline Urban & $14(13.9)$ & $87(86.1)$ & 1.0 & \\
\hline \multicolumn{5}{|l|}{ Religion: } \\
\hline ICatholic & $58(21.6)$ & $210(78.4)$ & $1.31(0.75-2.30)$ & 0.344 \\
\hline Others & $20(17.4)$ & $95(82.6)$ & 1.0 & \\
\hline \multicolumn{5}{|l|}{ Education level: } \\
\hline Tertiary & $4(18.2)$ & $18(81.8)$ & $0.86(0.28-2.62)$ & $0.793 \Psi$ \\
\hline Below tertiary & $74(20.5)$ & $287(79.5)$ & 1.0 & \\
\hline \multicolumn{5}{|l|}{ Ever used HM: } \\
\hline Yes & 70 (33.7) & $138(66.3)$ & $10.59(4.93-22.77)$ & $<0.001^{*}$ \\
\hline No & $8(4.6)$ & $167(95.4)$ & 1.0 & \\
\hline \multicolumn{5}{|l|}{ Self-medication: } \\
\hline Yes & $67(25.5)$ & $196(74.5)$ & $3.39(1.72-6.68)$ & $<0.001^{*}$ \\
\hline No & $11(9.2)$ & $109(90.8)$ & 1.0 & \\
\hline \multicolumn{5}{|l|}{ Income: } \\
\hline$<75,000$ & $57(22.7)$ & $194(77.3)$ & $1.32(0.73-2.39)$ & 0.353 \\
\hline$\geq 75,000$ & $18(18.2)$ & $81(81.8)$ & 1.0 & \\
\hline \multicolumn{5}{|l|}{ Socio-cultural factors: } \\
\hline \multicolumn{5}{|l|}{ Occupation: } \\
\hline Peasant & 64 (21.9) & $228(78.1)$ & $1.54(0.82-2.91)$ & 0.177 \\
\hline Others & $14(15.4)$ & 77 (84.6) & 1.0 & \\
\hline \multicolumn{5}{|l|}{ Marital status: } \\
\hline Married & $51(20.7)$ & $195(79.3)$ & $1.07(0.63-1.80)$ & 0.812 \\
\hline Not married & 27 (19.7) & $110(80.3)$ & 1.0 & \\
\hline \multicolumn{5}{|l|}{ Perception: } \\
\hline Effective/safe & $57(46.7)$ & 65 (53.3) & $10.02(5.67-17.73)$ & $<0.001^{*}$ \\
\hline Not effective & $21(8.0)$ & $240(92.0)$ & 1.0 & \\
\hline
\end{tabular}

$\Psi$ Fisher's Exact Test, ${ }^{*} P$-value significant $(<0.05)$, OR Odd's ratio, $\mathrm{Cl}=95 \%$ confidence interval, $\mathrm{HM}$ Herbal medicine. $\uparrow$ Catholic being the largest religious denomination in the district

finding similar to that previously reported by Yolan et al. (2007) in Zambia [9].

\section{Factors associated with use of herbal medicines}

Majority of the mothers who used herbal medicines during pregnancy perceived and believed that herbal medicines are effective and safe during pregnancy, a finding comparable to that by Azriani et al. (2008) in Malaysia [37]. This finding is also consistent wth previous findings by Mothupi (2014) in Nairobi, Kenya, were respondents used herbal medicine during pregnancy becasue of perception that western medicine was 'not working' and that herbal medicine was better or more effectice for their illness [30]. Similar findings have been reported by other authors [7, 31, 38], and could be explained by the fact that perception on the effectiveness of herbal medicines in solving problems will tend to influence whether mothers might use them again in the next pregnancy. More still, the above findings could also be related to cultural beliefs on causation of ill-health and belief that herbal medicines are inherently safe and cure many illnesses. Therefore, given that majority of the women do interface with the healthcare system at least once during their pregnancy, the healthcare providers should use this 
Table 6 Obstetric/maternal and health systems factors associated with use of herbal medicine during pregnancy

\begin{tabular}{|c|c|c|c|c|}
\hline Characteristics & Used HM N=78 (\%) & No HM use $N=305(\%)$ & OR $(95 \% \mathrm{Cl})$ & $p$-value \\
\hline \multicolumn{5}{|c|}{ Obstetric/maternal factors: } \\
\hline \multicolumn{5}{|l|}{ Parity: } \\
\hline Primiparous & $11(12.6)$ & $76(87.4)$ & $0.50(0.25-0.98)$ & $0.042^{*}$ \\
\hline Para $\geq 2$ & $69(22.6)$ & $229(77.4)$ & 1.0 & \\
\hline \multicolumn{5}{|c|}{ Used HM in previous preg } \\
\hline Yes & $54(44.6)$ & $67(55.4)$ & $7.98(4.45-14.30)$ & $<0.001^{*}$ \\
\hline No & $20(9.2)$ & $198(90.8)$ & 1.0 & \\
\hline \multicolumn{5}{|l|}{ ANC attendance: } \\
\hline Yes & $78(20.5)$ & $303(79.5)$ & $0.80(0.76-0.84)$ & $0.473 \Psi$ \\
\hline No & $0(0)$ & $2(100)$ & 1.0 & \\
\hline \multicolumn{5}{|l|}{ Number of ANC: } \\
\hline$<4$ & $42(21.5)$ & $153(78.5)$ & $1.18(0.72-1.96)$ & 0.508 \\
\hline$\geq 4$ & $35(18.8)$ & $151(81.2)$ & 1.0 & \\
\hline \multicolumn{5}{|l|}{ Place of birth: } \\
\hline H/Facility & $61(18.7)$ & $265(81.3)$ & $0.54(0.29-1.02)$ & 0.055 \\
\hline Home & $17(29.8)$ & $40(70.2)$ & 1.0 & \\
\hline \multicolumn{5}{|c|}{ Health system factors: } \\
\hline \multicolumn{5}{|l|}{ Distance from HF: } \\
\hline$>5 \mathrm{~km}$ & $48(28.4)$ & $121(71.6)$ & $2.43(1.46-4.05)$ & $0.001^{*}$ \\
\hline$\leq 5 \mathrm{~km}$ & $30(14.0)$ & $184(86.0)$ & 1.0 & \\
\hline \multicolumn{5}{|c|}{ Costs of health services: } \\
\hline Expensive & $49(23.2)$ & $162(76.8)$ & $1.49(0.89-2.49)$ & 0.124 \\
\hline Not expensive & $29(16.9)$ & $143(83.1)$ & 1.0 & \\
\hline \multicolumn{5}{|c|}{ Drug access in HFs: } \\
\hline Available & $42(17.6)$ & $197(82.4)$ & $0.64(0.39-1.06)$ & 0.080 \\
\hline Not available & $36(25.0)$ & $108(75.0)$ & 1.0 & \\
\hline
\end{tabular}

$\Psi$ Fisher's Exact Test, ${ }^{*} P$-value significant $(<0.05), O R$ Odd's ratio, $C l 95 \%$ confidence interval, HF Health facility, HM Herbal medicine

as an opportunity to sensitize them on the various limitations and potential adverse effects of herbal medicines, especially with regards to pregnancy.

Women who used herbal medicines during their previous pregnancies, as well as those who had ever used herbal medicines for other reasons were more likely to

Table 7 Multivariable logistic regression model for use of herbal medicines

\begin{tabular}{lll}
\hline Characteristics & AOR $(95 \% \mathrm{Cl})$ & $p$-value \\
\hline Age $(<35 / \geq 35$ years) & $1.05(0.42-2.60)$ & 0.915 \\
Self-medication (Yes/No) & $1.10(0.46-2.61)$ & 0.835 \\
Perception (effective/not effective) & $2.18(1.02-4.66)$ & $0.044^{*}$ \\
Distance from health facility $(>5 \mathrm{~km} / \leq 5 \mathrm{~km})$ & $1.45(0.71-2.97)$ & 0.310 \\
Ever used herbal medicine (Yes/No) & $3.87(1.46-10.25)$ & $0.006^{*}$ \\
Used HM in previous pregnancy (Yes/No) & $2.51(1.21-5.19)$ & $0.013^{*}$ \\
Parity (para 1/para $\geq 2)$ & $0.82(0.32-2.05)$ & 0.664 \\
\hline
\end{tabular}

${ }^{*} P$-value significant $(<0.05), O R$ Odd's ratio, $\mathrm{Cl} 95 \%$ confidence interval, $H M$ herbal medicine have used herbal medicines in their current pregnancies. This finding is consistent with that reported by Mothupi (2014) among postpartum women accessing public healthcare in Nairobi, Kenya [30], and suggests that the use of herbal medicines in previous pregnancy (cies) will likely predict their use in future pregnancies. The relatively common background use of herbal medicines in this setting as found in the present study was evidenced in one of the FGDs where six of the eight participants reported to have ever used herbal medicines for various other reasons. The above findings might be explained by the women's previous experiences with, and belief that herbal medicines worked in solving their other problems, as well as to its longstanding integration into the culture and its perception as their own indigenous medicine.

There was a tendency to higher use of herbal medicines during pregnancy among women from rural areas (23\%) compared to their urban counterparts (14\%). Relatedly, women living farther away (more than $5 \mathrm{kms}$ ) from any nearest health facility were twice more likely 
to use herbal medicines during pregnancy than those living less than $5 \mathrm{kms}$ from the nearest health facility, and this was statistically significant on bivariate analysis $(\mathrm{p}=0.001)$, though did not independently predict use of herbal medicines. This could be attributed to challenges of accessibility of health services, and supports a previous report by Mothupi (2014) in Nairobi, Kenya [30], and Mbwanji (2012) in Tanzania [39] that long distance to the nearest health facility was a significant factor associated with use of herbal medicine during pregnancy. This finding may not be surprising since long distance from health facility hinders access to modern healthcare by increasing costs of transportation, as well as time to access health services. Herbal products, being readily available, cheap and provided by members who are well known in the community, therefore becomes an easier alternative. This implies that addressing challenges of availability and accessibility of healthcare services should be an important consideration in addressing the prevalent use of herbal medicines during pregnancy in this population.

\section{Indications and characteristics of herbal medicine use}

Herbal medicines in the present study were used for multiple reasons including to relief symptoms such as fever, abdominal and waist pain, respiratory illnesses, and skin problems, as well as nausea and vomiting among others, a finding that resonates with that from several authors $[7,40,41]$. This finding has important implications given the fact that these are common symptoms which may indicate underlying serious complications during pregnancy such as severe malaria, or severe bacterial infections (urinary tract infections, pelvic inflammatory disease, septicaemia, or chorioamnionitis). This therefore calls for concerted health educations and community sensitizations as the use of herbal remedies may delay prompt diagnosis and effective treatment of these conditions with resultant adverse consequences to both the mother and fetus, including pregnancy wastage, a concern also previously highlighted by Kennedy et al. (2013) in a multinational study of herbal medicine use during pregnancy [6]. This scenario may also be important as a proxy indicator of lack of access to reliable healthcare services to the population, thereby calling for a thorough assessment of healthcare in the region.

Ingestion was the single most common method of using herbal medicine during pregnancy among the women in the study setting, with the other methods being smearing on the abdomen and insertion in the vagina, a finding similar to that by Kamatenesi and Oryem (2007) in a study in western Uganda [42]. These methods of usage, as found in the current and previous studies, may be attributed to the perceived actions and effects of the particular herbal products used, but with potential implications for interactions and interference with the routine orally ingested ANC medications. Similarly, the practice of particularly inserting herbal products in the vagina places these women at high risk of infections (genital tract infections), accidental rupture of membranes and pregnancy wastage. This finding therefore calls for concerted efforts in community sensitization in changing some of these potentially dangerious practices.

Herbal medicines in the study setting were mainly used during the second $(23 \%)$ and third $(21 \%)$ trimesters. Using herbal medicines during different trimesters of pregnancy may be associated with different effects, and shows great variation from one setting to another. For instance, in their study of herbal medicines use during pregnancy in western Uganda, Kamatenesi and Oryem (2007) found that herbal medicines were more commonly taken during labour (91\%) and in the third trimester $(40 \%)$, with very low use during the first trimester (7\%) [42]. In a Malaysian study, majority of the mothers took herbal medicines during the third trimester only (80\%), mainly to facilitate labour [37], a finding also reported by Rolanda and Sally (2006) in South Africa [43]. The variability in the timing of use of the herbal medicines could possibly be explained by the differences in the perceived desired effects and the reasons for use at a particular time; socio-cultural variability and belief, as well as differences in the types of herbs used by the different population groups. The use of herbal medicines during the first trimester as also found in the current study however raises concerns since this is the critical period of organogenesis, with potential risks for adverse effects like congenital anomalies.

A significant number of the users of herbal medicines during pregnancy in the current study used the herbal products concomitantly with the conventional medicines given during the antenatal care, a finding much higher than reported by Tabatabace (2011) in Iran [14]. In addition, more than half of the herbal medicine users during pregnancy reported to have not adhered to the conventional medicines dispensed during antenatal visits. This finding has an important policy implication as it presents a serious concern to components of the goal-oriented ANC interventions, especially prevention of maternal anaemia and malaria, as well as elimination of mother-to-child transmission when HIV positive expectant mothers do not adhere to antiretroviral drugs as a result of using herbal products. Furthermore, as suggested by Oshikoya et al. (2007) [44] and Chen et al. (2011) [45], concurrent use of herbal products with the conventional medicines as depicted in this study may result in interactions which may alter the pharmacokinetics of the drugs leading to an increase or decrease in plasma concentrations, thus altering the therapeutic outcomes. 


\section{Limitations of the study}

The study was conducted among postnatal mothers attending postnatal clinics which may have affected its generalizability since only a small proportion of mothers attend postnatal care. Similarly, the exclusion of emancipated minors who were not accompanied by adults is also likely to have affected the generalizability of the study findings. This study also included only two lower health facilities which may not be representative of the many health facilities at that level. However, attempt was made to overcome these shortcomings by triangulating the quantitative method with qualitative information collected within the local communities outside the health facilities. Information bias was also a likely problem since use of herbal medicines is very often perceived negatively by health workers, and hence some women may have feared admitting to use of herbal medicines.

\section{Conclusions}

The use of herbal medicines during pregnancy among women in Gulu district is common, which may be an indicator for poor access to conventional western healthcare. The factors associated with use of herbal medicines during pregnancy include believe that herbal medicines are effective and safe, and having ever used herbal medicines during previous pregnancies and for other reasons. Many users have confidence in the efficacy of herbal medicines as an alternative treatment, with oral ingestion being the major method of use.

This therefore calls for community sensitization drives on the dangers of indiscriminate use of herbal medicine in pregnancy, as well as integration of trained traditional herbalists and all those community persons who influence the process in addressing the varied health needs of pregnant women.

\section{Abbreviations}

ANC: Antenatal care; FGD: Focus group discussion; HC: Health center; KII: Key informant interview; SD: Standard deviation; UBOS: Uganda Bureau of Statistics; VHT: Village health team; WHO: World Health Organization

\section{Acknowledgements}

In a special way, I would like to thank the management and staff of Gulu district health office and the health facilities in which this study was done for making it possible to undertake this study in their facilities. A special tribute goes to the respondents who participated in this study.

\section{Funding}

This study was not funded by any external body.

\section{Availability of data and materials}

The dataset supporting the conclusions of this article is available on request to the corresponding author.

\section{Authors' contributions}

RN was the initiator of the study and contributed to the study design, data collection, and interpretation of results. NMT and AAH contributed to the study design, interpretation of results and drafting of the manuscript. All authors have read and approved the final manuscript.

\section{Competing interests}

The authors declare that they have no competing interests.

\section{Consent for publication}

Consent to publish this manuscript from the participants was deemed not applicable since the manuscript does not contain any individual person data.

Ethics approval and consent to participate

Approval to carry out the study was sought from Makerere University School of Public Health Higher Degrees, Research and Ethics Committee and the Uganda National Council for Science and Technology. Institutional consent to carry out the research were sought and obtained from the district leadership and the individual health facility management. Voluntary informed consent was obtained from the participants before participating in the study after explanation in the language they understood best, the nature and purpose of the study, the potential benefits and risks if any. Young mothers below 18 years of age were enrolled in the study if they were accompanied by another adult who gave informed consent allowing participation in the study. Confidentiality was observed throughout the study and participants' identifiers were used instead of names. Withdrawal from the study at any time was an option for those who wished to do so and this did not carry any penalty.

\section{Author details}

1Department of Paediatrics and Child Health, St. Mary's Hospital Lacor, P.O Box 180, Gulu District, Uganda. ²Department of Epidemiology and Biostatistics, Makerere University School of Public Health, Makerere University College of Health Sciences, P.O. Box 7072, Kampala, Uganda. ${ }^{3}$ Department of Disease Control and Environmental Health, Makerere University School of Public Health, Makerere University College of Health Sciences, P.O. Box 7072, Kampala, Uganda.

Received: 28 April 2016 Accepted: 4 October 2016

Published online: 06 October 2016

\section{References}

1. Ernst E. Herbal medicinal products during pregnancy: are they safe? Brit J Obs Gyn. 2002;109:227-35.

2. Nikolajsen $T$, Nielsen F, Rasch V, Sorensen PH, Ismail F, Kristiansen U, et al. Uterine contraction induced by Tanzanian plants used to induce abortion. J Ethnopharmacol. 2011;137(1):921-5.

3. World Health Organization. Traditional medicine. 2008. 12-01.

4. World Health Organization. WHO traditional medicine strategy 2002-2005 Geneva: World Health Organization; 2002.

5. World Health Organization. Traditional medicine Fact sheet $N^{\circ} 134,2008$. http://www.who.int/mediacentre/factsheets/2003/fs134/en/. Accessed 29 June 2016

6. Kennedy DA, Lupattelli A, Koren G, Nordeng $\mathrm{H}$. Herbal medicine use in pregnancy: results of a multinational study. BMC Complement Altern Med. 2013;13:355. http://www.biomedcentral.com/1472-6882/13/355.

7. Titilayo OK, Rasaq A, Ismail EM. Attitude and use of herbal medicines among pregnant women in Nigeria. BMC Complement Altern Med. 2009;9:53.

8. Gharoro EP, Igbafe AA. Pattern of drug use amongst antenatal patients in Benin City, Nigeria. Med SciMonit. 2000;6:84-7

9. Yolan B, Victoria C, Robert LG, Jeffrey SAS, Jennier FC, Moses S. Use of traditional medicine among pregnant women in Lusaka, Zambia. J Altern Complement Med. 2007;13(1):123-8.

10. Tabuti J, Lye K, Dhillion S. Traditional herbal drugs of Bulamogi, Uganda: plants, use, and administration. J Ethnopharmacol. 2003:88:19-44.

11. UBOS. Uganda Demographic and Health Survey 2011 report.

12. The Millennium Development Goals Report 2013.

13. Lamorde M, Tabuti JRS, Obua C, Kukunda CB, Lanyero H, Byakika-Kibwika P, et al. Medicinal plants used by traditional medicine practitioners for the treatment of HIV/AIDS and related conditions in Uganda. Journal of Ethnopharmacology, doi:10.1016/j.jep.2010.04.004

14. Tabatabace M. Use of herbal medicine among pregnant women referring to Valiasr Hospital in Kazeroon, Fars, South of Iran. J Med Plants. 2011; 10(37):96-108.

15. Farah $\mathrm{MH}$, Edward $\mathrm{R}$, Lindquist $\mathrm{M}$, et al. International monitoring of adverse health effects associated with herbal medicines. Pharmacoepidemiol Drug Saf. 2000;9(2):105-12. 
16. Veale DJH, Havlik I, Katsoulis LC, et al. The pharmacological assessment of herbal oxytocics used in South African traditional medicine. Biomed Environ. 1998;2:216-22.

17. Sulaiman SA, Mohsin SSJ, Chatterjee A. An indigenous herbal formulation and its contraceptive profile in rats. Biomed Res. 2001;12:65-9.

18. Chan LY, Chiu PY, Lau TK. An in-vitro study of guisenoside Rb1-induced teratogenicity using a whole rat embryo culture model. Hum Reprod. 2003; 18:2166-8.

19. Gruber CW, O'Brien M. Uterotonic plants and their bioactive constituents. Planta Med. 2011;77(3):207-20. doi:10.1055/s-0030-1250317.

20. Mabina MH, Pitsoe SB, Moodley J. The effect of traditional herbal medicines on pregnancy outcome. The King Edward VIII hospital experience. S Afr Med J. 1997;87(8):1008-10.

21. Tsui B, Dennehy C, Tsourounis C. A survey of dietary supplement use during pregnancy at an academic medical center. Am Obs Gyn. 2001;185:433-7.

22. Lacroix I, Damase-Michael C, Lapeyre-Mestre M, Montastrue JL. Prescription drugs during pregnancy in France. Lancet. 2000;356:1735-6.

23. Seely D, Dugoua JJ, Perri D, Mills E, Koren G. Safety and efficacy of panax ginseng during pregnancy and lactation. Can J Clin Pharmacol. 2008;15(1): e87-94. Epud 2008 Jan 18.

24. Dugoua JJ, Perri D, Seely D, Mills E, Koren G. Safety and efficacy of cohosh (caulophyllum thalictroides) during pregnancy and lactation. Can J Clin Pharmacol. 2008;15(1):e66-73. Epud 2008 Jan 18.

25. Goel RK, Prabha T, Kumar MM, et al. Teratogenicity of asparagus racemosus wild root, a herbal medicine. Indian J Exp Biol. 2006:44(7):570-3.

26. Cuzzolin L, Zaffani S, Murgai V, Gangemi M, Menghelli G, Chiamenti GP, et al. Patterns and perceptions of complementary/alternative medicine among paediatricians and patients' mothers: a review of the literature. Eur J Pediatr. 2003;162(12):820-7. Epub 2003 sep 26.

27. Conover EA. Herbal agents and over-the-counter medications in pregnancy Best Pract Res Clin Endocrinol Metab. 2003;17(2):237-51.

28. Adams C, Cannel S. Women's beliefs about "natural" hormoner and natural hormones replacement therapy. Menopause. 2001;8(6):433-40.

29. Langloid-Klassen D, Kipp W, Jahngri GS, Rubaaale J. Use of traditional medicine by aids patients in Kabarole District, Western Uganda. Am J Trop Med Hyg. 2007;77(4):757-63.

30. Mothupi MC. Use of herbal medicine during pregnancy among women with access to public healthcare in Nairobi, Kenya: a cross-sectional survey. BMC Complement Altern Med. 2014;14:432.

31. Laelago T, Yohannes T, Lemango F. Prevalence of herbal medicine use and associated factors among pregnant women attending antenatal care at public health facilities in Hossana town, Southern Ethiopia: facility based cross sectional study. Archives Public Health. '2016;74:7. doi:10.1186/s13690-016-0118-z.

32. Rasch V, Sørensen PH, Wang AR, Tibazarwa F, Jager AK. Unsafe abortion in rural Tanzania - the use of traditional medicine from a patient and a provider perspective. BMC Pregnancy Childbirth. 2014;14:419.

33. Uganda Bureau of Statistics Census Report 2002.

34. Leslie K. Survey sampling. New York: John Wiley and Sonsa; 1965. p. 59-60.

35. Mbura JS, Mgaya HN, Heggenhougen HK. The use of oral herbal medicine by women attending ANC in urban and rural Tanga distirct in Tanzania. East Afr Med J. 1985;8:540-50.

36. Della AF, Angela D, Gemma W, Melissa B, Elizabeth M. Herbal medicine use during pregnancy in a group of Australian women. BMC Pregnancy Childbirth. 2006;6:21.

37. Azriani Ab R, Siti AS, Zulkifli A, Wan NW, Abdul M. Prevalence and pattern of use of herbal medicines during pregnancy in Tumpat district, Kelantan. Malays J Med Sci. 2008;15(3):40-8.

38. Astin JA. Why do people choose and use complementary therapies? In: Ernst E, editor. Complementary medicine and objective appraisal. Oxford: Butterworth-Heinemann; 1996.

39. Mbwanji J. Prevalence of herabl medicine use and associated factors among pregnant women attending antenatal clinic at Mbeya Referral Hospital in 2010. http://ir.muhas.ac.tz:8080/jspui/handle/123456789/41.

40. Hollyer T, Boon H, Georgousis A, Smith M, Einarson A. The use of CAM by women suffering from nausea and vomiting during pregnancy. BMC Complement Altern Med. 2002;2:1-6.

41. Nordeng $\mathrm{H}$, Havnen $\mathrm{G}$. Use of herbal drugs in pregnancy: a survey among 400 Norwagian women. Pharmacoepidemiol Drug Safety. 2004;13:371-80.

42. Kamatenesi-Mugisha M, Oryem-Origa $\mathrm{H}$. Medicinal plants used to induce labour during childbirth in western Uganda. J Ethnopharmacol. 2007;109:1-9.
43. Rolanda VDK, Sally T. Traditional medicine in late pregnancy and labour: preceptions of kgaba remedies amongst the Tswana in South Africa. Afr J Trad CAM. 2006;3:11-22.

44. Oshikoya KA, Njokanma OF, Chukwura HA, et al. Adverse drug reactions in Nigerian children. Paediatr Perinat Drug Ther. 2007;8:81-8.

45. Chen XW, Serag ES, Sneed KB, et al. Clinical herbal interactions with conventional drugs: from molecules to maladies. Curr Med Chem. 2011;18:4836-50.

\section{Submit your next manuscript to BioMed Central and we will help you at every step:}

- We accept pre-submission inquiries

- Our selector tool helps you to find the most relevant journal

- We provide round the clock customer support

- Convenient online submission

- Thorough peer review

- Inclusion in PubMed and all major indexing services

- Maximum visibility for your research

Submit your manuscript at www.biomedcentral.com/submit
) Biomed Central 